\title{
ICTs and Music in Special Learning Disabilities
}

\author{
https://doi.org/10.3991/ijes.v4i3.6066 \\ Athanasios S. Drigas and Paraskevi Theodorou \\ NCSR DEMOKRITOS, Institute of Informatics and Telecommunications, Net Media Lab, Athens, Greece
}

\begin{abstract}
This study is a critical review of published scientific literature on the use of Information and Communication Technologies (ICT), Virtual Reality, multimedia, music and their applications in children with special learning difficulties. Technology and music are two factors that are recognized as tools which ensure quality of life, success and access to knowledge and learning resources. In the following papers of the last decade (2006-2015) are proposed models of music therapy for students with special learning difficulties in a psycho educational setting. There are also defined future research perspectives concerning the applications of technology in this particular research field.
\end{abstract}

Index Terms-Special learning difficulties, Dyslexia, Attention Deficit Hyperactivity Disorder (ADHD), Autistic Spectrum Disorders

\section{INTRODUCTION}

Concerning learning disabilities, novel word learning is regarded as problematic for children with severe language impairments. Electronic storybooks when used to support vocabulary acquisition are quite effective [1]. E-learning and e-teaching are used in different educational contexts promoting the inclusion of students with special disabilities in education [2]. There is also a description of a usability evaluation of a web portal so as to meet the needs of people with learning disabilities, especially around the period of "transition" [3]. Effectiveness of iPad computerized writing instruction was evaluated for the 4th - 9th graders with diagnosed specific learning disabilities (SLD) affecting writing like dysgraphia, dyslexia, oral and written language learning disability [4]. This is a clinical case study of a three year old girl called Lily with childhood apraxia of speech (CAS) and the effects that music therapy has on her treatment [5]. Considering the learning difficulties that students with Special Educational Needs (SEN) face every day, the development of a multimedia Learning Environment (LE) is introduced in the next study [6].

As far as dyslexia is concerned, there is a critical review on the use of Virtual Reality (VR) and its applications in developmental dyslexia [7]. Furthermore the next study enhances learning via critical thinking, multimodal learning and motivational approaches [8]. Children with DD can be helped a lot, by music teachers, because of the temporal nature of cognitive issues in the disorder [9]. Afterwards there is an emphasis on IMLO (Interactive Multimedia Learning Object) [10].

Music therapy is ideal for students with emotional and behavioral disorders (EBD) [11]. Illustrating the reflection of a composer's or performer's emotions onto his/her music, it seems that there is also a relation between musical expression and psychopathology, which is shown in the work of great composers [12]. Another study investigates leisure activities, particularly Internet activities, among boys and girls with ADHD and compares these with children from the general population [13].

A framework was developed for carers (teachers and parents) to help them create personalized social stories for children with autistic spectrum disorders (ASDs) [14]. The use of $i \operatorname{Pad} 2 \AA$ for students with autism runs on a 10 step task analysis, which examines the effects of systematic instruction [15]. Digital technology contributes with a multidimensional forum for the creation and implementation of social stories [16]. In order to test this hypothesis that individuals with autism are less responsive to the emotional content of music than typical ones, there was a comparison of a group of high-functioning autistic adults with a group of normal emotional responsiveness to music [17]. A multimedia platform analysis is developed using web standards which focuses on children's individual interests [18]. New horizons have appeared with the advent of touch screen that allows a more natural interaction for children with cognitive and motor impairments [19]. The article emphasizes in music therapy and virtual environments for assisting children with ASD socializing via music activities, using techniques of music therapy, which include free and structured musical improvisation [20]. The proceeding study provides an empirical evaluation of a music intervention for high functioning adolescents and young adults with ASD using a music program called 'SoundScape' [21]. A set of videogames, called Pictogram Room Project for children and adults with autistic spectrum disorder (ASD) in Spain is implemented next [22]. Finally two projects are presented: the Virtual Reality applications Research Team (VIRART) and the COSPATIAL [23].

\section{CATEGORIES OF SPECIAL LEARNING DIFFICULTIES}

\section{A. Learners with Reading and Writing Difficulties}

Although it is difficult for children with severe language impairments to learn fast, electronic storybooks when used to support vocabulary acquisition is quite effective [1]. A total of 23 kindergarten SLI children heard 8 storybooks each four times: (a) two static stories without music or sounds, (b) two static stories with music or sounds, (c) two video stories without music or sounds, and (d) two video books with music or sounds. All the experiments showed that story book reading is very effective language intervention for SLI children (Severe Language Impairments). There might be some limitations in word learning concerning the memory capacity to these children. The more time one spends on the computer (listening to music), especially when reading e-books even without adults support the more familiar with difficult words can become [1].

E-learning and e-teaching are both applied by teachers at all levels of education [2]. Electronic teacher includes a system of learner and teacher activities. The educators 
should have specific qualifications which are defined by the professional standards. This method covers people who suffer from specific learning disabilities like dyslexia, dysgraphia and dyscalculia. Inclusive teaching meets the learning needs of all students acknowledging that their disabilities and individual learning needs demand special treatment including multimedia environments, multisensory teaching, music and role-play games [2].

Transition is when young people with disabilities move from school based support to life in the community [3]. The basic aim of the research was to test the usability and how the participants could navigate the site and understand information. Music plays an important role as a method of improving learners' abilities. Therefore it is quite extensively used. Thus, they use YouTube with bollywood dancing, pop music, videos and sports clips. In addition to these activities, participants use the software application Paint, play free games, listen to music, use email, watch DVDs and do simultaneously school work, free browsing of the portal. Moreover there are certain possibilities like scrolling, navigating back, recognizing the previous page and undertaking less directed web site activity. Above all, the most important conclusion is that people with mild learning difficulties can be adept with web technology and music [3].

Students with a history of specific language impairment (SLI) experience more computer anxiety than typically developing peers, so they strongly need to get used to working with their computers [4]. The research aim was to determine whether students with SLDS who have persisting writing problems beyond the third grade would show response to instruction on computer lessons. Musical rhythm is of great importance in achieving higher levels of progress among people with the former disorders. There are certain improvements. However one drawback is that the research was conducted after school when participants were obviously tired and thus we cannot have accurate results. Another one is that it happened in a rare basis. A most important question arises in the future about the added value of hybrid human and technology teachers [4].

The music therapy treatment involved a mixture of behavioral, improvisational, and creative approaches in what has been termed a data-based music therapy approach [5]. There is an argument whether CAS is a disorder related to overall language development or a neurological disorder affecting the brain. The acquisition of language and/or speech for an apraxia of speech case needs extensive practice, instruction, time, and repetition. Music interventions can be effective in developing specific speech sounds, complementing the work of the speech language therapist. Conclusively, music therapy treatment appeared to be very beneficial for Lily in socialization, motor skills, movement, verbal communication, cognitive and emotional. The data-based treatment approach outlined by Hanser (1999) allowed for changes in treatment techniques based on Lily's progress [5].

Usability tests of the system match with the needs of people with cognitive disabilities. The usability tests consisted of graded activities drown from various special educational needs (SEN) sources [6]. The function is quite simple combining the intellectual level of tasks with the physical ease-of-use of the system. A wide variety of methods with music is presented dealing with problems and encouraging independent learning. Future improve- ments are promising for professional educators, researchers and developers [6].

\section{B. Dyslexia}

This is a critical review on the use of Virtual Reality (VR) and its applications in developmental dyslexia [7]. The purpose of this research is to: (a) identify the potential contribution of Virtual Environments in the disorder's screening, assessment, awareness process and intervention, (b) present a synthesis of the available empirical evidence and (c) define future research perspectives. It focuses on visuospatial and nonverbal problem skills. Also it concentrates on memory and awareness for dyslexia. The unique technological characteristics of VR include: interaction, immersion, presence, transduction and conceptual change. Conclusively VR technologies contribute in a very positive way towards the dyslexics and their families [7].

This paper emphasizes in the scientific usage of technologies in school applications [8]. This study specifies technology as hardware, software, high-tech and low-tech. The technologies are divided into 5 groups (Marshala, 2000): (i) Written language technologies - for examples spell checkers, proofreading, speech synthesizers, speech recognition, outlining, brain storming/mind mapping, word prediction and alternative keyboards. (ii) Reading technologies - optical character recognition (read text back out loud), speech synthesis/screen review, tape recorders and variable speech control. (iii) Listening technologies - Personal FM listening. (iv) Organization/Memory technologies - personal data managers \& free-form databases. (v) Math technologies - talking calculators \& electronics math worksheets. Finally the combination of music and technology education accelerates concentration and interest [8].

In the music classroom with the aid of multisensory teaching using rhythm and rhythmic dictation, music concepts may be learned more easily [9]. Moreover the use of colors is quite effective in the learning process. The main aims of this article are to introduce a brief overview of Developmental Dyslexia (DD) and to provide teaching strategies for music educators to assist children with DD through music, melodic and rhythmic activities in the music classrooms [9].

Analyzing this work there is an emphasis in the implementation of multimedia elements used for instructions on IMLO (Interactive Multimedia Learning Object), which is a multimedia software prototype about multiplication of two topics developed for dyslexic children in Malaysia [10]. A presentation of background study and research method is available. The approach for this research is qualitative, where the multimedia elements are interpreted using ARCS model. The main objective of this research is to present the functions of multimedia elements in IMLO's learning and exercise activities. Available guidelines in this literature for implementing multimedia elements were based on learning theory and model [10].

\section{Attention Deficit Hyperactivity Disorder (ADHD) and Attention Deficit Disorder (ADD) Learners}

The objective of this work is the impact of music therapy to students with EBD and the proposal of a model of music therapy for them in a psychoeducational setting [11]. These mentally imbalanced students have short attention spans, difficulties relating to people, low self- 
esteem and family problems. They are generally easily frustrated. Therefore music therapy contributes positively to communication, behavior and self-confidence. Music therapy programs are applied in schools and residential settings using reading comprehension, phonetics and meaning interpretation. Finally a combination of music and technology is a non-invasive medium that enhances self-expression, self-esteem, motor skills, coordination, socialization, creativity, inventiveness, independence and success. Music is a great reinforce and motivator for human beings [11].

The reflection of the emotions and psychology of famous composers is clearly illustrated in their work showing possible psychopathological disorders [12].For example, Max Graf was interested in Wagner, Eduard Hitschmann wrote on Schumann and Brahms while Richard and Edith Sterba worked on Beethoven. Furthermore other phychoanalysts like Theodor Reik, one of Freud's earliest students, demonstrated that musical structure can represent feelings. The main aim here is to explore the potential reflection of psychiatric semiology and symptomatology of a patient diagnosed with Obsessive Compulsory Disorder (OCD) onto her musical improvisation. There were three interactive music sessions with the MIROR, a machine learning based system. The results show that aspects of the patient's pathology can be associated with musical attributes and structures. On the whole the influence, the impact and the reflection of music is very obvious in relation to human psychology and character. For example a patient's logorrhea is translated into non-stop playing, impulsivity becomes intensive playing and fast tempo reflects anxiety [12].

The current study provides new insight into several leisure activities, including a variety of specific Internet activities, particularly online and video games that characterize leisure among boys and girls with ADHD, compared with adolescents from the general population [13]. Leisure activities can provide adolescents with an opportunity to develop skills and competencies, increased physical and psychological development, and a sense of belonging. Conclusively internet activities, especially social communities and downloading music, might provide adolescents with ADHD with accessible means of social interaction where individuals can interact with each other in physical and virtual spaces [13].

\section{Learners with Autistic Spectrum Disorders}

In this paper a framework is introduced to help teachers create personalized social stories for children with autistic spectrum disorders (ASDs) [14]. It outlines an intervention to reveal the hidden code that underpins social interactions to them. Additionally it focuses on how technology can facilitate the implementation of this intervention by utilizing multimedia-authoring tools. The tools which are used are social stories approach and technical enhancements to teach social skills. There is a design of reach and teach framework, which is divided in three parts (tutorials, sample and template activities). After the implementation of the used procedure the findings revealed an individualization of social stories. Finally, the fact that children with ASDs are visual learners makes the social stories an ideal approach due to the use of visual information to emphasize the meaning [14].

The next concerns an introduction of $\mathrm{iPad} 2 \AA$ which includes constant time delay and a modified system of least prompts, paired with an iPad $2 \AA$ via shared stories for students with limited verbal ability [15]. The sessions occurred in two self-contained special education classrooms within a small suburban elementary school in the Southeast. Among the three authors, the third was a music therapist. This study measured the effects of the independent variable package like shared stories, delivered via the $\mathrm{iPad} 2 \mathbb{R}$ and the dependent variables (independent correct responses of student and on listening comprehension questions). Conclusively, multimedia capabilities of the $\mathrm{iPad} 2 \AA$ emphasized on auditory and optical tasks, which increased accessibility for all students. There are limitations of this study which cannot be generalized to other students with developmental disabilities. The increasing focus of academic proportions for students with developmental disabilities can extend the research base with the help of technology [15].

Digital media, like photography is an efficient and flexible method to create stories to teach social skills [16]. Peer tutoring and social stories are extensively used together with digital media. The use of digital media involves visual supports and self-monitoring, which are effective strategies for young children (Odom et al., 2003). These methods include identification of target behaviors, composition of digital stories scripts, obtaining and organizing pictures and finally the creation of stories on PowerPoint. Above all, it is essential to help children with disabilities to take ownership of learning as early as possible so that they do not feel helpless [16].

Individuals with high-functioning autism are less responsive to the emotional content of music than typical ones. Here there is a comparison to test this hypothesis [17]. The definition of alexithymia is the lack of ability to verbalize the individuals' emotions. According to the mediation analysis of this study there is a two stage model of musical emotions. The emotions are divided in three categories: happy, sad and scary. The results showed that students with autism had no reduced responsiveness to the musical stimuli compared to the control group. In conclusion the question is what mechanism can explain the responsiveness of music at the second stage. It might be that there is something intrinsic to autism that makes it hard to verbally describe what causes the physiological arousal by music [17].

A multimedia platform analysis is developed using web standards which focuses on children's individual interests [18]. The proposed system which was developed is based in multimedia content (video, images, audio and stories). This application encourages socialization and facilitating interaction among children with ASD and allows tutors to easily customize the contents and look-and-feel of the tool. The framework was designed for both the end users and the tutors with a rich multimedia content with the help of web technologies. There are some challenges and limitations that must be overcome like dependency to a tutor, the need to respect a daily routine, the difficulty in dealing with spontaneous or unexpected moments and different levels of severity. In conclusion we can assess if adapting this application will give a mean for children to interact with peers [18].

A hypothesis is that the use of a computer stimulates curiosity, content customization and peer communication [19]. One touch screen for children with cognitive and motor impairments is a genuine idea. Most applications allow children to communicate through images, to create 
storyboards, or to reproduce preferable content using sound. MyTroc@s.net focuses on promoting the acquisition of new competences at the communication level, by using content customized for the preferences of each child. The development of myTroc@s.net is an evolution of a previous solution. There is a framework which produces different types of log (applications, face detection, likes, activities and messages) through which we can audit the child's behavior. All in all myTroc@s.net emerged from the real-world needs of special education teachers [19].

The use of music therapy can encourage active participation of autistic children, providing a motivating environment for knowledge acquisition and socialization skills [20]. The Music therapist helps the patient to promote health, using musical experiences and relationships that develop through them. The use of virtual reality environment facilitates communication through the process of speech and musically stimulates the thought process. Music activities in virtual environments require various cognitive resources, such as visual processing and verbal memory, auditory and motor programming. The use of virtual reality environments can reject social abandonment and isolation, contributing to socio-emotional development. Finally VR technology contributes a lot in the recovery of patients [20].

The music program for young adults with ASD and for high functioning adolescents which is called 'SoundScape', was an eight-week program consisting of 90minute weekly music sessions [21]. The program is focused on self-esteem, anxiety, attitudes and relationships with peers as these are pervasive challenges for those with ASD. The outcome showed a memorable increase in selfesteem, reduced anxiety and better attitudes toward peers. Bearing in mind that this pilot study examines the impact to people with ASD through participation in a music program, the challenge is to fight physical, psychological stress, low self-esteem, verbal disability and depression. Consequently music (video and music technology) is a very positive factor to facilitate multisensory integration for all children. Last but not least, a continuous improvement of the efficacy of music participation for autistic children should be introduced emphasizing in a broader range of evaluation tools, empirical methods and a longterm investigation of positive outcomes [21].

Here it is introduced a set of videogames for children and adults with autistic spectrum disorder (ASD) in Spain [22]. The main aim of the Pictogram Room Project was to achieve a pedagogic pattern for entities with autism whose developmental abilities are most affected by the disorder. This particular program underlines the importance of playability criteria and self awareness for children with autism. Pedagogy proposes that music is an excellent auxiliary method to support visual techniques such as video games when addressing people with ASD. Since there is an exponential evolution of technology, impaired individuals can use their own bodies and gestures as a "natural interaction" procedure without the use of other tools. In the end the combination of new technologies and therapeutic intervention open treatment options that are highly promising [22].

The Virtual Reality applications Research Team (VIRART) have explored issues concerning development and evaluation of virtual reality environments (VR/VEs) for children with autism [23]. Another project was the AS
Interactive which is developing virtual environments for social skill training in young people with Asperger Syndrome. There is also COSPATIAL, Collaborative Virtual Environments for Interaction and Learning in children on the Autism Spectrum. COSPATIAL seeks to utilize, collaborative virtual environments (CVEs) rather than the single user VE developed previously in the AS Interaction Project (Cobb, 2007). Sound including music is optional. However, there has been a lack of research into how technology can be designed inclusively with the input of the target user group. In the case of this work, we focus on the supervisory adult and the child with autism [23].

\section{CONCLUSIONS}

The aim of this study, given the multitude of manifestations of special educational needs was to examine the most representative studies over the last decade exploiting ICT and music and how the combination of those contributes to independent pupil learning and curriculum. Realizing the enormous development of technological devices, it is quite natural to be used to deal with people with various disabilities overcome their problems and communicate or interact with the surrounding world. Nevertheless there is extensive ongoing research about the great effects of technology in music therapy.

\section{REFERENCES}

[1] Smeets, D. J., Van Dijken, M. J., \& Bus, A. G. "Using Electronic Storybooks to Support Word Learning in Children with Severe Language Impairments". Journal of Learning Disabilities, Vol. 47(5), pp. $435-449$ (2014) http://dx.doi.org/10.1177/00222194 12467069

[2] Bjekić, D., Obradović, S., Vučetić, M., \& Bojović, M. "E-teacher in Inclusive e-education for Students with Specific Learning Disabilities". Procedia - Social and Behavioral Sciences, 128, pp. 128133 (2014) http://dx.doi.org/10.1016/j.sbspro.2014.03.131

[3] Williams, P., \& Hanson-Baldauf, D. "Testing a web information portal for people with learning disabilities". Journal of Research in Special Educational Needs, 10(1), 42-51 (2010) http://dx.doi.org/10.1111/j.1471-3802.2009.01142.x

[4] Berninger, V. W., Nagy, W., Tanimoto, S., Thompson, R., \& Abbott, R. D. "Computer instruction in handwriting, spelling, and composing for students with specific learning disabilities in grades 4-9". Computers \& Education, 81, pp. 154-168 (2015) http://dx.doi.org/10.1016/j.compedu.2014.10.005

[5] Beathard, B., \& Krout, R. E. "A music therapy clinical case study of a girl with childhood apraxia of speech: Finding Lily's voice". The Arts in Psychotherapy, 35(2), pp. 107-116 (2008) http://dx.doi.org/10.1016/j.aip.2008.01.004

[6] Williams, P., \& Nicholas, D. "Testing the usability of information technology applications with learners with special educational needs (SEN)". J Research in Spec Educ Needs, 6(1), pp. 31-41 (2006) http://dx.doi.org/10.1111/j.1471-3802.2006.00057.x

[7] Kalyvioti, K., \& Mikropoulos, T. " A Virtual Environments and Dyslexia: A Literature Review". Procedia Computer Science, 27, pp. 138-147 (2014) http://dx.doi.org/10.1016/j.procs.2014.02.017

[8] Felicia, A., Sharif, S., Wong, W. K., Marriappan, M. "Innovation of assistive technologies in Special Education: A Review ".International Journal of Enhanced Research in Educational Development (IJERED). Vol. 2, Issue 3, pp. 25-38 2014

[9] Heikkila, E., \& Knight, A. "Inclusive Music Teaching Strategies for Elementary-Age Children with Developmental Dyslexia". Music Educators Journal, 99(1), pp. 54-59 (2012) http://dx.doi.org/10.1177/0027432112452597

[10] R. S. Fadilahwati Abdul Rahman, Fattawi Mokhtar, Nor Aziah Alias, "Multimedia Elements as Instructions for Dyslexic Children," International Journal Of Education And Information Technologies, Vol. 6, No. 2 (2012)

[11] Sausser, S., \& Waller, R. J. "A model for music therapy with students with emotional and behavioral disorders". The Arts in 
Psychotherapy, 33(1), pp. 1-10, (2006) http://dx.doi.org/10.1016/ j.aip.2005.05.003

[12] Dakovanou, X., Anagnostopoulou, C., Triantafyllaki, A. "The Reflection of Psychiatric Semiology and Symptomatology on $\mathrm{Mu}-$ sical Structure: A Case Study of a Patient Diagnosed with Obsessive Compulsive Disorder". Proceedings of the 12th international conference on Music Perception and Cognition and the 8th Triennial Conference of the European Society for the Cognitive Sciences of Music. Thessaloniki, Greece, pp 242-247 (2012)

[13] Bolic, Baric, V., Hellberg, K., Kjellberg, A., \& Hemmingsson, H. "Internet Activities During Leisure: A Comparison Between Adolescents With ADHD and Adolescents From the General Population". Journal of Attention Disorders, pp.1-9 (2015) http://dx.doi.org/10.1177/1087054715613436

[14] Doyle, T., \& Arnedillo-Sánchez, I. "Using multimedia to reveal the hidden code of everyday behaviour to children with autistic spectrum disorders (ASDs) ". Computers \& Education, 56(2),pp. 357-369 (2011) http://dx.doi.org/10.1016/j.compedu.2010.08.016

[15] Spooner, F., Ahlgrim-Delzell, L., Kemp-Inman, A., \& Wood, L. A. "Using an $\mathrm{iPad} 2(\mathrm{R})$ With Systematic Instruction to Teach Shared Stories for Elementary-Aged Students With Autism". Research and Practice for Persons with Severe Disabilities, Vol. 39(1), pp. 30-46 (2014) http://dx.doi.org/10.1177/1540796 914534631

[16] More, C. "Digital Stories Targeting Social Skills for Children With Disabilities: Multidimensional Learning". Intervention in School and Clinic, Vol. 43(3), pp.168-177 (2008) http://dx.doi.org/10.1177/1053451207312919

[17] Allen, R., Davis, R., \& Hill, E. "The Effects of Autism and Alexithymia on Physiological and Verbal Responsiveness to Music". $J$ Autism Dev Disord, 43(2), pp. 432-444 (2012) http://dx.doi.org/10.1007/s10803-012-1587-8

[18] Da Silva, M. L., Gonçalves, D., Guerreiro, T., \& Silva, H. "A Web-based Application to Address Individual Interests of Children with Autism Spectrum Disorders". Procedia Computer Science, Vol. 14, pp. 20-27 (2012) http://dx.doi.org/10.1016/ j.procs.2012.10.003

[19] Silva, M. L., Gonçalves, D., \& Silva, H. "User-tuned Content Customization for Children with Autism Spectrum Disorders". Procedia Computer Science, 27, pp. 441-448 (2014) http://dx.doi.org/10.1016/j.procs.2014.02.048

[20] Lima, D., \& Castro, T. "Music Spectrum: A Music Immersion Virtual Environment for Children with Autism". Procedia Computer Science, Vol. 14, pp. 111-118 (2012) http://dx.doi.org/10.1016/j.procs.2012.10.013
[21] Hillier, A., Greher, G., Poto, N., \& Dougherty, M. "Positive outcomes following participation in a music intervention for adolescents and young adults on the autism spectrum". Psychology of Music, 40(2), pp. 201-215 (2011) http://dx.doi.org/10.1177/0305 $\underline{735610386837}$

[22] Herrera, G., Casas, X., Sevilla, J., Rosa, L., Pardo, C., Plaza, J. "Pictogram Room: Natural Interaction Technologies to Aid in the Development of Children with Autism". Vol 08, pp. 39-44 (2012)

[23] Millen R., Edlin-White and Cobb S. "The Development of Educational Collaborative Virtual Environments for Children with Autism L". Proceedings of the 5th Cambridge Workshop on Universal Access and Assistive Technology. Cambridge (2010)

\section{AUTHORS}

Athanasios Drigas is a Research Director at IITN.C.S.R. Demokritos. He is the Coordinator of Telecoms $\mathrm{Lab}$ and founder of Net Media Lab since 1996. From 1990 to 1999 he was the Operational manager of the Greek Academic network. He has been the Coordinator of Several International Projects, in the fields of ICTs, and eservices (e-learning, e-psychology, e-government, einclusion, e-culture etc). He has published more than 270 articles, 7 books, 25 educational CD-ROMs and several patents. He has been a member of several International committees for the design and coordination of Network and ICT activities and of international conferences and journals. Also he has accepted several distinctions for his work (articles, projects, patents) (email:dr@iit.demokritos.gr).

Theodorou Paraskevi has a MA in Special Education and a Msc in Digital Systems and Telecommunications. She is a Teaching Professional in Information and Communication Technologies (ICTs). She is also a Teacher of Music playing and the Theory of music. She has participated in various research projects regarding the use of ICTs in Special Education. She is with Net Media Lab of NCSR Demokritos (e-mail: vantheodorou@sch.gr and van4.theodorou@gmail.com ).

Submitted 20 July 2016. Published as resubmitted by the authors 05 October 2016. 